\title{
The effect of age on the response to the pneumococcal polysaccharide vaccine
}

\author{
Hyunju Lee ${ }^{1,2}$, Moon H Nahm³ ${ }^{3}$ Kyung-Hyo Kim ${ }^{1,2^{*}}$
}

\begin{abstract}
Background: Streptococcus pneumoniae is a leading cause of morbidity and mortality in the elderly. To prevent invasive pneumococcal diseases, the 23-valent pneumococcal polysaccharide vaccine (PPV) is recommended in subjects over 65 years of age. Although it has been reported to provide approximately 50-80\% protection against invasive disease in the general elderly population, there is still controversy as to the effectiveness of the PPV in the elderly.
\end{abstract}

Methods: To evaluate the immune response to the pneumococcal polysaccharide vaccine in the elderly, samples from young adults and elderly were obtained before and one month after vaccination. The quantitative and qualitative response to the vaccine were measured by the ELISA and opsonophagocytic killing assay for eight vaccine type serotypes (4, 6B, 9V, 14, 18C, 19A , 19F, 23F) and one vaccine-related serotype (6A).

Results: The response to the pneumococcal polysaccharide vaccine showed a similar response between adults and elderly when evaluated by the ELISA, however the functional activity of the antibodies elicited after vaccination were lower in the elderly group for more than half of the serotypes evaluated. In comparison of the antibody needed for 1:8 opsonic titer, more antibodies were needed in the elderly for serotypes Pn 4, 19F, 23F and $6 \mathrm{~A}$, suggesting the functional activity of antibody detected by the ELISA was lower in the elderly compared with the adult group for these serotypes. As for subjects with an opsonic titer $<8$ after vaccination, only one subject each for serotypes Pn 4, 9V and 6A were found in the adult group. However, up to 10 (30.3\%) of the subjects did not show opsonic activity after vaccination in the elderly group for serotypes $\mathrm{Pn} 4,9 \mathrm{~V}, 14,19 \mathrm{~A}$ and $6 \mathrm{~A}$.

Conclusions: Although the amount of antibodies elicited were similar between the two age groups, distinct differences in function were noted. This report highlights the importance of a quantitative and qualitative evaluation of the immunogenic response to the PPV in the elderly age group.

Trial registration: This trial is registered with Clinical trials.gov. Registration number NCT00964769

\section{Background}

Streptococcus pneumoniae is an important pathogen worldwide causing infection of the respiratory tract, bacteremia, and meningitis and a leading cause of morbidity and mortality in young children and the elderly. To prevent invasive pneumococcal diseases, the 23 -valent pneumococcal polysaccharide vaccine (PPV) is recommended in subjects aged 65 years and over [1]. It provides approximately $50-80 \%$ protection against invasive disease in the general elderly population [2], although

\footnotetext{
* Correspondence: kaykim@ewha.ac.kr
'Department of Pediatrics, School of Medicine, Ewha Womans University,

* Correspondence: kaykim@ewha.ac.kr
'Department of Pediatrics, School of Medicine, Ewha Womans University, Seoul, Republic of Korea
}

(c) 2010 Lee et al; licensee BioMed Central Ltd. This is an Open Access article distributed under the terms of the Creative Commons Attribution License (http://creativecommons.org/licenses/by/2.0), which permits unrestricted use, distribution, and reproduction in any medium, provided the original work is properly cited.

there is still controversy as to the effectiveness of the PPV in the elderly [3,4].

While the effectiveness of vaccine can be demonstrated by clinical studies directly, clinical studies may not be easy to perform. An alternative to clinical studies is to assess the immune responses to vaccine, 'a surrogate of protection'. For the pneumococcal vaccine evaluation, the concentration of type specific antibody measured with enzyme-linked immunosorbent assay (ELISA) has been applied. However, many observations indicate that the antibody's ability to enhance opsonophagocytosis should be the preferred measure of pneumococcal vaccine-induced immunity [5].

In the elderly, the immune response of PPV measured with ELISA is as much as that in young adults [6-9]. 
However, the response evaluated by the ELISA in the elderly; the previously used $2^{\text {nd }}$ generation ELISA is known to show little specificity due to cross-reaction with contaminants in the capsular polysaccharide (PS), and although the method has gone through improvements [10-13], nonfunctional antibodies can be detected. Also, there is possibility that the elderly may produce pneumococcal antibodies with sufficient avidity to bind capsular PS adsorbed on ELISA plates, but with insufficient avidity to induce opsonophagocytosis [6], result in producing antibodies that are less opsonic than those produced by young adults. But there are few reports of the opsonic function after the vaccine in the elderly $[6,14]$.

Therefore, to determine the immune response in the elderly age group against the PPV, we performed the ELISA and opsonophagocytic killing assay (OPKA) in pre- and postvaccine sera. The response was compared with healthy adults, which the effectiveness of the vaccine in healthy adults is already established [3,4]. The response was evaluated for eight vaccine type serotypes $(4,6 \mathrm{~B}, 9 \mathrm{~V}, 14,18 \mathrm{C}, 19 \mathrm{~A}, 19 \mathrm{~F}, 23 \mathrm{~F})$ which are prevalent serotypes of invasive diseases and to which the immunogenicity have been studied widely in various age groups after the introduction of the 7-valent protein conjugate pneumococcal vaccine. Also, due to the fact that crossprotection for 6A in PPV vaccinated subjects has been anticipated but not widely proved, the immune response to the vaccine-related serotype $6 \mathrm{~A}$ was evaluated.

\section{Methods}

\section{Subjects and Sera Collection}

The study group consisted of subjects over 65 years of age and the control group included subjects under the age of 45 years. The subjects in both age groups were healthy volunteers. All subjects had no previous pneumococcal vaccination history and exclusion criteria included asplenia, cancer, liver or renal failure and history of hypersensitivity to vaccine. Vaccinees in both groups were not immunocompromised and this study did not include patients on chemotherapy, steroid or immunomudulating treatment, diabetes mellitus, alcoholism and chronic lung disease. Paired sera were collected from all participants. Prevaccine sera were obtained just before vaccination and postvaccine sera were obtained 4-6 weeks following vaccination. Sera were stored at $-70^{\circ} \mathrm{C}$ until analysis.

The study protocol was approved by the Institutional Review Board and was conducted in accordance with the Declaration of Helsinki and Good Clinical Practice guidelines and written consent was obtained before enrollment.

\section{Vaccine}

All subjects received a single intramuscular injection

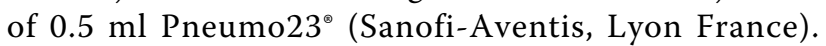

A $0.5 \mathrm{ml}$ dose of PPV contains 25 micrograms of purified capsular polysaccharide from each of 23 serotypes $(1,2,3,4,5,6 \mathrm{~B}, 7 \mathrm{~F}, 8,9 \mathrm{~N}, 9 \mathrm{~V}, 10 \mathrm{~A}, 11 \mathrm{~A}, 12 \mathrm{~F}, 14,15 \mathrm{~B}$, $17 \mathrm{~F}, 18 \mathrm{C}, 19 \mathrm{~A}, 19 \mathrm{~F}, 20,22 \mathrm{~F}, 23 \mathrm{~F}$ and $33 \mathrm{~F})$.

\section{ELISA anti-PS IgG Antibody Concentrations}

Anti-pneumococcal ( $\mathrm{Pn})$ antibodies against vaccine serotypes $4,6 \mathrm{~B}, 9 \mathrm{~V}, 14,18 \mathrm{C}, 19 \mathrm{~F}$ and $23 \mathrm{~F}$ and vaccinerelated serotype $6 \mathrm{~A}$ were measured by $3 \mathrm{rd}$ generation ELISA using both C-PS and 22F serotype capsular PS absorption, as previously described [10,13]. Briefly, each well of a 96-well medium binding microtiter plate (Corning Inc., Corning, NY) was coated with $100 \mu \mathrm{l}$ of a serotype-specific pneumococcal PS antigen (American Type Culture Collection [ATCC], Manassas, Va.) diluted to a predetermined concentration (Serotype 6A PS was a gift from G. Schiffman), and plates were incubated at $37^{\circ} \mathrm{C}$ for 5 hours in a humidified chamber. The coated plates were washed with $1 \times$ Tris-buffered saline with $0.01 \%$ Brij 35 solution. Test sera were preabsorbed with C-PS (Statens Serum Institut, Copenhagen, Denmark) and 22F capsular PS (ATCC), and the reference standard 89-SF (provided by Carl Frasch, Center for Biologics Evaluation and Research, Food and Drug Administration, Bethesda, MD.) was preabsorbed with C-PS. The pre-absorbed sera and 89-SF were serially diluted 2.5-fold in absorption solution and incubated at $25^{\circ} \mathrm{C}$ for 30 minutes. After incubation, the sera $(50 \mu \mathrm{l})$ were transferred to the coated microtiter plates, and the plates were incubated for 2 hours at $25^{\circ} \mathrm{C}$. The plates were washed 5 times, and $100 \mu \mathrm{l}$ of diluted alkaline phosphatase-conjugated goat anti-human IgG (Southern Biotech, Birmingham, AL) was added to each well. After 2-hour incubation, the plates were washed 5 times, and $100 \mu \mathrm{l}$ of substrate solution \{diethanolamine (Sigma, St. Louis, MO.) with $1 \mathrm{mg} / \mathrm{ml} p$-nitrophenyl phosphate powder (Sigma)\} was added to each well. After 2-hour incubation at $25^{\circ} \mathrm{C}, 50 \mu \mathrm{l}$ of $3 \mathrm{M} \mathrm{NaOH}$ was added to all wells to stop the enzyme reaction. The optical density was measured at $405 \mathrm{~nm}$ and $690 \mathrm{~nm}$ using an ELISA microplate reader. Optical densities were converted to antibody concentrations using the CDC software for pneumococcal ELISA (written by Brian Plikaytis at the Centers for Disease Control and Prevention, Atlanta, GA. It can be downloaded free of charge from http://www.cdc.gov/ncidod/dbmd/bimb/elisa.htm). A detailed protocol can be found at a website http://www.vaccine.uab.edu.

\section{Opsonophagocytic Killing Assay (OPKA)}

The opsonic activities of the samples were evaluated by a double-serotype OPKA, as previously described $[15,16]$. Briefly, HL-60 cells were differentiated into granulocytic cells by culturing them in RPMI 1640 with 
$10 \%$ fetal calf serum and $0.8 \%$ dimethylformamide (Fisher Scientific, Pittsburgh, Pa.) for 5 days. After differentiation, HL-60 cells were diluted to $10^{7}$ cells $/ \mathrm{ml}$ in Hanks' buffer supplemented with $0.1 \%$ gelatin and $10 \%$ fetal calf serum. Test samples (serum) were also diluted in the same buffer. Target strains expressing capsule type $4,6 \mathrm{~A}, 6 \mathrm{~B}, 9 \mathrm{~V}, 14,18 \mathrm{C}, 19 \mathrm{~A}, 19 \mathrm{~F}, 23 \mathrm{~F}$ with antibiotic resistance to optochin or streptomycin were reported $\left(\sim 2 \times 10^{5} \mathrm{cfu} / \mathrm{ml}\right.$ of each serotype) [15]. Equal volumes of two bacterial suspensions that were chosen to be analyzed together, were pooled. Ten microliters of pneumococcal solution containing $1,000 \mathrm{CFU}$ and $20 \mu \mathrm{l}$ of test sample were placed in each well of a 96 -well microtiter plate. After $30 \mathrm{~min}$ of incubation at $25^{\circ} \mathrm{C}, 40 \mu \mathrm{l}$ of HL60 cell suspension $\left(4 \times 10^{5}\right.$ cells per well $)$ and $10 \mu \mathrm{l}$ of baby rabbit complement (Pelfreeze, Browndeer, Wis.) were added to each well. The mixture was incubated for $1 \mathrm{~h}$ at $37^{\circ} \mathrm{C}$ with shaking. Five microliters of the reaction mixture was plated on two different Todd-Hewitt agaryeast extract plates. After the fluid was absorbed into the agar, one plate was overlaid with molten ToddHewitt agar $(0.75 \%)$ containing yeast extract (0.5\%), 0.5 $\mathrm{mg}$ of optochin/liter and $100 \mathrm{mg}$ of TTC (Sigma)/liter [15]. The other plate was overlaid with Todd-Hewitt agar containing yeast extract, $100 \mathrm{mg}$ of streptomycin/ liter, and TTC. After an overnight incubation in a candle jar at $37^{\circ} \mathrm{C}$, the number of bacterial colonies in the agar plates was enumerated using an automated colony counter. Opsonic titer was defined as the serum dilution that kills $50 \%$ of bacteria and was determined by linear interpolation.

\section{Statisics}

Geometric mean concentrations (GMCs) of anti-pneumococcal IgG antibodies, geometric mean titers (GMT) of opsonic titer, geometric mean potency (GMP) for antibody potency and geometric mean indices (GMI) for antibody needed for 1:8 opsonic titer were evaluated and two-sided $95 \%$ confidence intervals (CIs) were determined to each pneumococcal serotype. Serum samples with opsonic titer $<8$ were assigned a value of 4 for analysis purposes. A two-tailed Mann-Whitney U-test was used to analyze differences between pre and post vaccine sera and between age groups. Reverse cumulative distribution curves were used to display percentages of subjects that achieved different opsonic titer or potency to each of the pneumococcal serotypes.

\section{Results}

\section{Subjects}

Thirty-three subjects were enrolled in the elderly group. The age of these subjects ranged from 65 to 70 years (median 66 years). Among these subjects, 20 were male and 13 were female.
The control group consisted of twenty-four adult subjects under the age of 45 years, range from 24 to 37 years. Among these subjects, 13 were male and 11 were female.

\section{Specific Antibody Concentration by ELISA}

The GMCs and 95\% CIs for pre- and post-immune antiPn IgG concentrations are shown in Table 1. After immunization, the GMC increased significantly in seven out of the eight serotypes evaluated in each age group. Anti-Pn 6A IgG did not increase significantly, which is not included in the PPV.

In a comparison of GMCs between the elderly and adult groups, preimmune and postimmune GMCs did not show a difference between age groups except for $\mathrm{Pn}$ 4 and $6 \mathrm{~A}$.

\section{Antibody Function by OPKA}

The GMTs and 95\% CIs for pre- and postimmune opsonic titers are shown in Table 1. The GMT increased significantly after immunization for all serotypes in both the adult and elderly groups. OPKA was done in limited patients for serotype Pn 14 due to lack of sera \{Adults $(\mathrm{N}=10)$, Elderly $(\mathrm{N}=20)\}$.

In the preimmune sera, no difference in GMT was seen between the elderly and adult age groups. However, after immunization, GMT was higher in the adult group for four out of nine serotypes evaluated; Pn 4, 14, 19A and $6 \mathrm{~A}$.

The reverse cumulative distribution curves for postimmune opsonic titers are shown in Fig. 1 and the data in Table 2 present percentages of subjects who achieved certain opsonic titers to each serotype.

Before immunization, the number of subjects with no detectable opsonic activity (opsonic titer $<8$ ) ranged from 3 (12.5\%) for Pn 23F to 17 (70.8\%) for Pn 4 in the adult group and 7 (21.2\%) for Pn 14 to 27 (81.8\%) for Pn 4 in the elderly group. However after vaccination, in the adult group, all subjects showed opsonic activity for serotypes Pn 6B, 14, 18C, 19A, 19F and 23F. Whereas in the elderly group, subjects with no detectable opsonic activity were noted for serotypes Pn 4, 9V, 14, 19A and 6A \{range $1(3.0 \%)$ for Pn $9 \mathrm{~V}$ to 10 (30.3\%) for Pn 4 \}. Number of subjects with no detectable opsonic activity for each serotype is shown in Table 3 . In the elderly group, $2(6.1 \%)$ subjects did not show detectable opsonic activity for 3 serotypes and $2(6.1 \%)$ subjects for 2 serotypes.

Antibody potency was measured by dividing the opsonic titer by the antibody concentration for each serotype (Table 3) [8]. Although there was no difference in GMP of specific antibody between the two age groups in the preimmune sera (except for Pn 6A), after immunization, antibody potency was significantly higher in the adult 
Table 1 Geometric means for antibody concentration and opsonization titers (Elderly, $\mathrm{N}=33$; Adults, $\mathrm{N}=24$ )

\begin{tabular}{|c|c|c|c|c|c|c|c|c|c|c|c|c|c|}
\hline \multirow[t]{2}{*}{ Serotype } & \multirow[t]{2}{*}{ Age } & \multicolumn{3}{|c|}{ Pre-IgG concentration $(\mu \mathrm{g} / \mathrm{mL})$} & \multicolumn{3}{|c|}{ Post-lgG concentration $(\mu \mathrm{g} / \mathrm{mL})$} & \multicolumn{3}{|c|}{ Pre-Opsonic titer (OT) } & \multicolumn{3}{|c|}{ Post-Opsonic titer (OT) } \\
\hline & & GMC & $95 \% \mathrm{Cl}$ & Sig & GMC & $95 \% \mathrm{Cl}$ & Sig & GMT & $95 \% \mathrm{Cl}$ & Sig & GMT & $95 \% \mathrm{Cl}$ & Sig \\
\hline \multirow[t]{2}{*}{4} & Adult & 0.43 & $0.32-0.59$ & $P<0.05$ & 2.21 & $1.61-3.05$ & $P<0.05$ & 17 & $6-47$ & NS & 1300 & $694-2437$ & $P<0.05$ \\
\hline & Elderly & 0.27 & $0.22-0.34$ & & 1.29 & $0.88-1.89$ & & 10 & $5-20$ & & 220 & $85-569$ & \\
\hline \multirow[t]{2}{*}{$6 B$} & Adult & 1.06 & $0.75-1.50$ & NS & 6.17 & $3.51-10.85$ & NS & 364 & $104-1270$ & NS & 8023 & $5747-11202$ & NS \\
\hline & Elderly & 1.17 & $0.85-1.61$ & & 7.73 & 4.13-14.48 & & 175 & $65-473$ & & 5495 & 3823-7898 & \\
\hline \multirow[t]{2}{*}{$9 \mathrm{~V}$} & Adult & 1.08 & $0.66-1.77$ & NS & 6.05 & $4.22-8.68$ & NS & 504 & 136-1867 & NS & 6380 & $3097-13140$ & $P=0.05$ \\
\hline & Elderly & 0.71 & $0.51-0.99$ & & 5.54 & $3.62-8.49$ & & 229 & $81-649$ & & 4506 & $2654-7649$ & \\
\hline \multirow[t]{2}{*}{$14^{\mathrm{a}}$} & Adult & 3.02 & $1.56-5.86$ & NS & 18.7 & $9.91-35.29$ & NS & 237 & 71-795 & NS & 6036 & 4091-8907 & $P<0.05$ \\
\hline & Elderly & 1.92 & $1.26-2.93$ & & 10.12 & $6.47-15.83$ & & 579 & $192-1748$ & & 4673 & 2298-9501 & \\
\hline \multirow[t]{2}{*}{$18 \mathrm{C}$} & Adult & 1.10 & $0.72-1.67$ & NS & 5.8 & $3.53-9.52$ & NS & 675 & 236-1931 & NS & 7226 & 5167-10105 & NS \\
\hline & Elderly & 0.95 & $0.64-1.42$ & & 6.77 & $4.42-10.37$ & & 273 & 104-717 & & 6698 & $4481-10012$ & \\
\hline \multirow[t]{2}{*}{$19 \mathrm{~A}$} & Adult & ND & & ND & ND & & ND & 59 & $21-170$ & NS & 2995 & $1919-4675$ & $P<0.05$ \\
\hline & Elderly & ND & & & ND & & & 27 & $12-58$ & & 556 & $252-1227$ & \\
\hline \multirow[t]{2}{*}{$19 F$} & Adult & 3.28 & $2.38-4.52$ & NS & 8.42 & 5.42-13.1 & NS & 40 & 15-105 & NS & 2082 & $1409-3075$ & NS \\
\hline & Elderly & 2.87 & $2.17-3.81$ & & 7.18 & 5.18-9.95 & & 43 & 19-97 & & 1183 & 759-1843 & \\
\hline \multirow[t]{2}{*}{$23 \mathrm{~F}$} & Adult & 0.60 & $0.37-0.99$ & NS & 3.22 & $1.91-5.41$ & NS & 485 & $183-1286$ & NS & 3101 & $2027-4746$ & NS \\
\hline & Elderly & 0.70 & $0.48-1.01$ & & 5.8 & $3.64-9.23$ & & 269 & 111-653 & & 3314 & 2152-5101 & \\
\hline \multirow[t]{2}{*}{$6 \mathrm{~A}$} & Adult & 1.62 & $1.19-2.22$ & $P<0.05$ & 2.39 & $1.78-3.21$ & NS & 54 & $17-171$ & NS & 2097 & $1041-4226$ & $P<0.05$ \\
\hline & Elderly & 3.25 & $2.21-4.79$ & & 4.01 & $2.81-5.72$ & & 17 & $9-36$ & & 244 & $102-587$ & \\
\hline
\end{tabular}

pre vs post $P<0.05$

${ }^{\mathrm{a}}$ For $\mathrm{Pn} 14$ OPKA was done in a limited patients due to lack of sera \{Adults $(\mathrm{N}=10)$, Elderly $(\mathrm{N}=20)$ \}

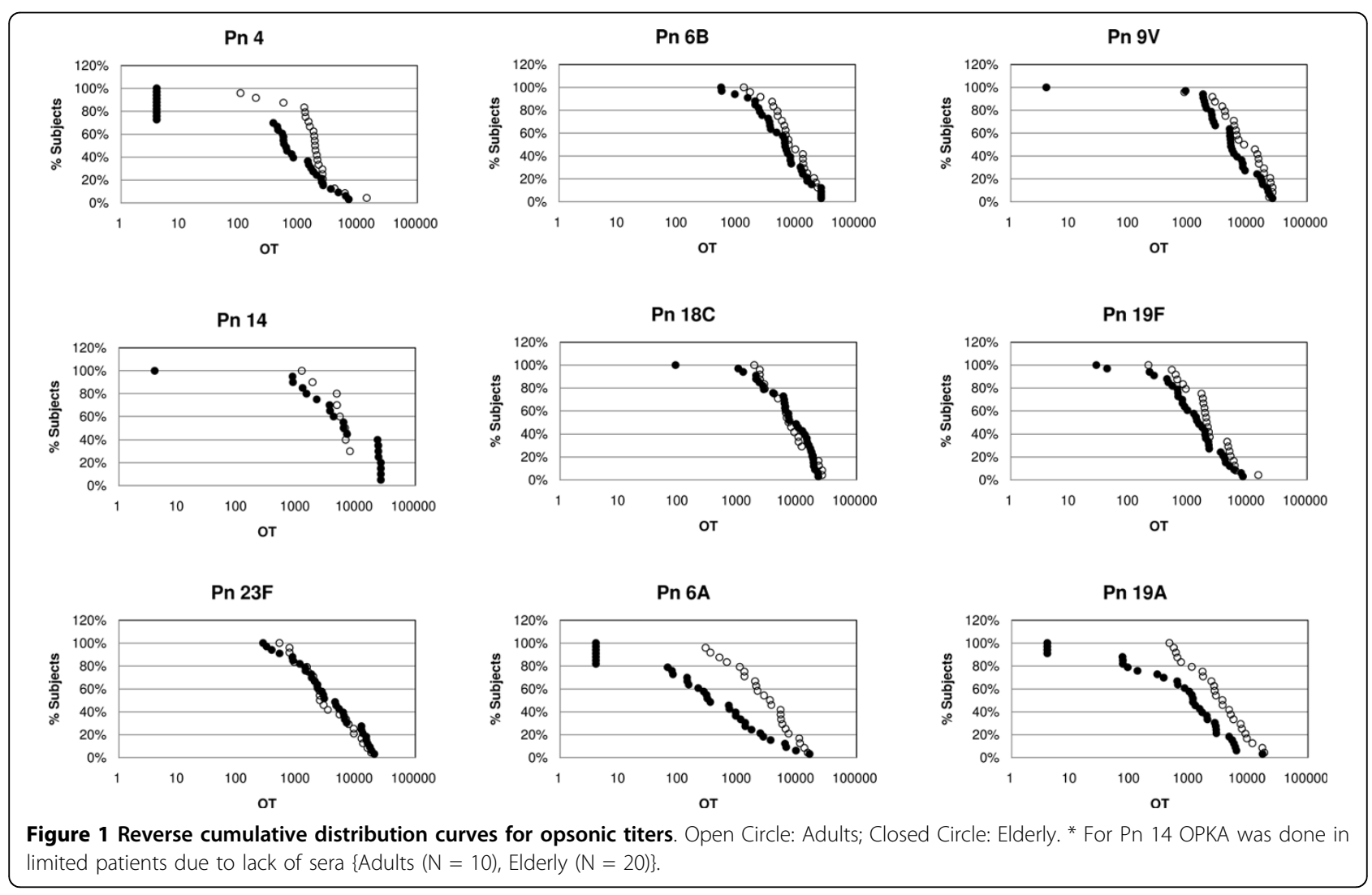


Table 2 Subjects with opsonic titer $<8$ pre- and post-vaccination

\begin{tabular}{lcccc}
\hline Serotype & \multicolumn{2}{c}{ Pre-vaccination Opsonic titer<8 } & \multicolumn{2}{c}{ Post-vaccination Opsonic titer<8 } \\
\cline { 2 - 5 } & Adult $(\mathrm{N}=24) \mathrm{n} /(\%)$ & Elderly $(\mathrm{N}=33) \mathrm{n} /(\%)$ & Adult $(\mathrm{N}=24) \mathrm{n} /(\%)$ & Elderly $(\mathrm{N}=33) \mathrm{n} /(\%)$ \\
\hline 4 & $17(70.8 \%)$ & $27(81.8 \%)$ & $1(4.2 \%)$ & $10(30.3 \%)$ \\
$6 \mathrm{~B}$ & $7(29.2 \%)$ & $11(33.3 \%)$ & $0(0.0 \%)$ & $0(0.0 \%)$ \\
$9 \mathrm{~V}$ & $7(29.2 \%)$ & $11(33.3 \%)$ & $1(4.2 \%)$ & $1(3.0 \%)$ \\
$14^{\mathrm{a}}$ & $7(29.2 \%)$ & $7(21.2 \%)$ & $0(0.0 \%)$ & $2(6.1 \%)$ \\
$18 \mathrm{C}$ & $4(16.7 \%)$ & $8(24.2 \%)$ & $0(0.0 \%)$ & $4(12.1 \%)$ \\
$19 \mathrm{~A}$ & $11(45.8 \%)$ & $17(51.5 \%)$ & $0(0.0 \%)$ & $0(0.0 \%)$ \\
$19 \mathrm{~F}$ & $12(50.0 \%)$ & $14(42.4 \%)$ & $0(0.0 \%)$ & $0(0.0 \%)$ \\
\hline 23F & $3(12.5 \%)$ & $7(21.2 \%)$ & $1(4.2 \%)$ & $7(21.2 \%)$ \\
\hline $\mathrm{A}$ & $12(50.0 \%)$ & $21(63.6 \%)$ & & \\
\hline
\end{tabular}

${ }^{a}$ For Pn 14 OPKA was done in a limited patients due to lack of sera \{Adults $(N=10)$, Elderly $\left.(N=20)\right\}$.

Table 3 Geometric means for antibody potency and antibody needed for 1:8 opsonization index (Elderly, $N=33$; Adults, $\mathbf{N}=\mathbf{2 4}$ )

\begin{tabular}{|c|c|c|c|c|c|c|c|c|c|c|c|}
\hline \multirow[t]{2}{*}{ Serotype } & \multirow[t]{2}{*}{ Age } & \multicolumn{3}{|c|}{$\begin{array}{c}\text { Pre-Antibody potency } \\
\text { (OT/[IgG]) }\end{array}$} & \multicolumn{3}{|c|}{$\begin{array}{l}\text { Post-Antibody potency } \\
\text { (OT/[IgG]) }\end{array}$} & \multicolumn{2}{|c|}{$\begin{array}{l}\text { Pre-Antibody needed for 1:8 } \\
\text { opsonization index (ng/ml) }\end{array}$} & \multicolumn{2}{|c|}{$\begin{array}{c}\text { Post-Antibody needed for 1:8 } \\
\text { opsonization index }(\mathrm{ng} / \mathrm{ml})\end{array}$} \\
\hline & & $\overline{G M P}$ & $95 \% \mathrm{Cl}$ & Sig & GMP & $95 \% \mathrm{Cl}$ & Sig & GMI & Sig & GMI & Sig \\
\hline \multirow[t]{2}{*}{4} & Adult & 42 & $16-111$ & NS & 633 & $372-1076$ & $P<0.05$ & 191.4 & NS & 12.6 & $P<0.05$ \\
\hline & Elderly & 37 & $18-73$ & & 171 & $77-378$ & & 218.6 & & 46.7 & \\
\hline \multirow[t]{2}{*}{$6 \mathrm{~B}$} & Adult & 343 & $102-1153$ & NS & 1349 & $743-2451$ & NS & 23.3 & NS & 5.9 & NS \\
\hline & Elderly & 150 & 57-392 & & 710 & 418-1209 & & 53.5 & & 11.3 & \\
\hline \multirow[t]{2}{*}{$9 \mathrm{~V}$} & Adult & 458 & $145-1448$ & NS & 1112 & $554-2233$ & NS & 17.5 & NS & 7.2 & NS \\
\hline & Elderly & 324 & $126-834$ & & 813 & 466-1417 & & 24.7 & & 9.8 & \\
\hline \multirow[t]{2}{*}{$14^{\mathrm{a}}$} & Adult & 63 & $23-172$ & NS & 423 & $202-886$ & NS & 126.1 & NS & 18.9 & NS \\
\hline & Elderly & 248 & $71-860$ & & 426 & $211-859$ & & 32.3 & & 18.8 & \\
\hline \multirow[t]{2}{*}{$18 C$} & Adult & 641 & $242-1699$ & NS & 1440 & $951-2182$ & NS & 12.5 & NS & 5.6 & NS \\
\hline & Elderly & 286 & $121-677$ & & 990 & 655-1497 & & 28.0 & & 8.1 & \\
\hline \multirow[t]{2}{*}{$19 \mathrm{~A}$} & Adult & ND & & ND & ND & & ND & ND & ND & ND & ND \\
\hline & Elderly & ND & & & ND & & & ND & & & \\
\hline \multirow[t]{2}{*}{$19 F$} & Adult & 12 & $5-30$ & NS & 276 & $195-391$ & $P<0.05$ & 653.2 & NS & 29.0 & $P<0.05$ \\
\hline & Elderly & 15 & $7-31$ & & 165 & $128-212$ & & 535.7 & & 48.5 & \\
\hline \multirow[t]{2}{*}{$23 \mathrm{~F}$} & Adult & 789 & 309-2012 & NS & 982 & 650-1482 & $P<0.05$ & 10.1 & NS & 8.1 & $P<0.05$ \\
\hline & Elderly & 386 & $170-879$ & & 571 & $396-824$ & & 20.7 & & 14.0 & \\
\hline \multirow[t]{2}{*}{$\overline{6 A}$} & Adult & 32 & $11-96$ & $P<0.05$ & 888 & $444-1774$ & $P<0.05$ & 249.1 & $P<0.05$ & 9.0 & $P<0.05$ \\
\hline & Elderly & 5 & $3-11$ & & 61 & 28-134 & & 1486.5 & & 131.3 & \\
\hline
\end{tabular}

${ }^{\text {a }}$ For Pn 14 OPKA was done in a limited patients due to lack of sera \{Adults $(N=10)$, Elderly $(N=20)$ \}.

group for four out of eight serotypes, including Pn 4 , $19 \mathrm{~F}, 23 \mathrm{~F}$ and $6 \mathrm{~A}$. The reverse cumulative distribution curves for the postimmune antibody potency are shown in Fig. 2.

Amount of antibody needed for 1:8 opsonic titer (GMI) was evaluated by dividing the antibody concentration $(\mathrm{ng} / \mathrm{ml})$ by the opsonic titer and multiplying by 8 (Table 3) [8]. There was no difference in measurements between the age groups in the pre-vaccine sera. However, after vaccination, GMI was significantly higher in the elderly group for serotypes Pn 4, 19F, 23F and 6A.

\section{Discussion}

After vaccination with PPV, although the amount of antibodies elicited were similar between the two groups, distinct differences in function were noted. After vaccination, the opsonic activity was lower in the elderly group against more than half of the serotypes evaluated. Also, in the analysis for antibody needed for 1:8 opsonization, more antibodies were needed in the elderly for serotypes Pn 4, 19F, 23F and 6A suggesting the functional activity of antibodies detected by the ELISA is lower in the elderly compared with the adult group for 


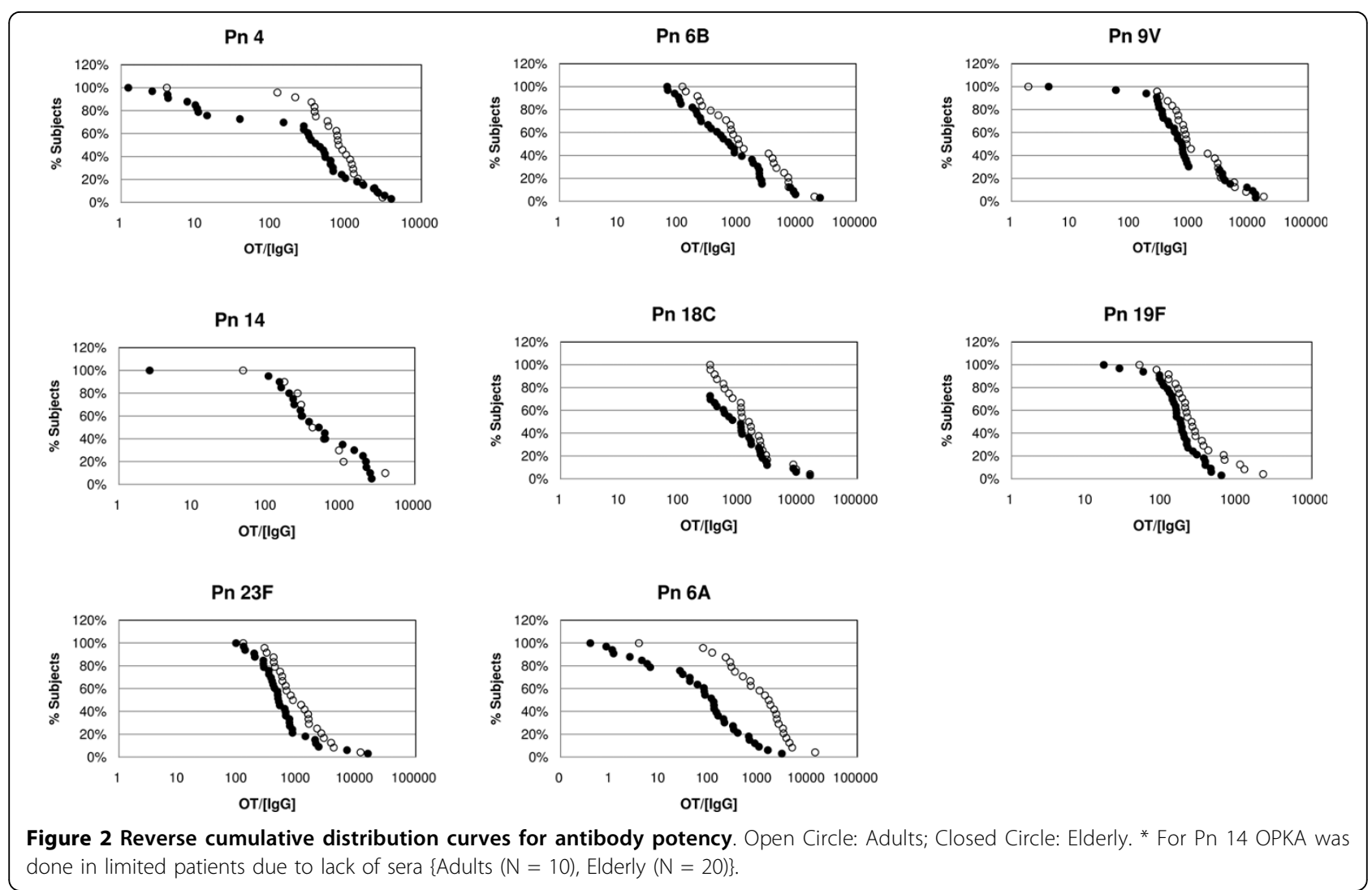

these serotypes. Moreover, whereas almost all subjects showed detectable opsonic activity after vaccination in the adult group, up to $10(30.3 \%)$ of the subjects did not show opsonic activity in the elderly group for serotypes Pn 4, 9V, 14, 19A and 6A

Recently, Schenkein et al. reported the opsonic antibody response to the PPV in the elderly [14]. In the article, the opsonic titer and antibody potency showed a significant difference between young and old adults for all 7 serotypes (Pn 4, 6B, 9V, 14, 18C, 19F and 23F) evaluated. Our results showed functional differences for 6 out of 9 serotypes evaluated (Pn 4, 14, 19A, 19F, 23F and $6 \mathrm{~A}$ ). The fact that the elderly subjects in our study were fairly younger (range 65-70 years, median 66 years) could be an explanation for difference in results. Functional decrease in the activity of antibodies has been reported to be more pronounced in the elderly as age increased [6]. Also in previous reports, the antibody titer after vaccination with PPV was better in male elderly compared with females [7] and the majority of the elderly subjects in our study were male.

The prevaccine antibody concentration and opsonic titer were similar between the age groups. Also the antibody needed for 1:8 opsonic titer was similar in the prevaccine sera of the elderly and adults. This is interesting considering rates and mortality from pneumococcal diseases are higher in the elderly group. This could be due to the fact that the subjects in this study were 65-70 years (median 66 years) of age. However, the susceptibility of elderly persons is multifactorial and nonimmunologic factors such as suppression of gag reflex, underlying disease predominate, with chronic cardiopulmonary and other diseases contribute to this. Romero-Steiner et al. reported prevaccination opsonic titers of elderly recipients to be lower when compared with younger adults, where the subjects ranged from age 63-103 years (mean 85.5 years) [6], but the control group consisted of a limited number of subjects $(n=12)$. Further research on older aged elderly subjects would be desirable.

The results of our study reflect the effect of aging on the B-cell immune system. In the elderly, the B cell production rate decreases, however the number of peripheral B cells remain constant $[17,18]$. This is due to the capacity of B cell for peripheral self-renewal and their increased life span when new B cells are not produced. However, whereas the magnitude of antibody response to T-independent antigens is maintained during aging, the quality of these antibodies alters during aging [19]. The change of affinity results from compromised selection of high affinity antibodies within the germinal center $[19,20]$. 
In this study, we evaluated the response to the vaccine-related serotype Pn 6A. The prevaccine anti-Pn 6A antibody concentration seemed to be higher in the elderly, however after vaccination, the opsonic titer was significantly higher in the adult group. Also, the antibody needed for 1:8 opsonic titer was more than 14 times higher in the elderly group. Although a crossreactive immune response was elicited to $\mathrm{Pn} 6 \mathrm{~A}$ in both groups, a much weaker response was seen in the elderly. Pn 6A is not included in the PPV. Only Pn 6B was included in the PPV because antibodies to the two serotypes were thought to be highly cross-reactive, and Pn $6 \mathrm{~B}$ is a more stable antigen [21]. The striking difference between age groups in immunogenic response to Pn 6A was an interesting finding which suggests with vaccination of PPV in the elderly, the effectiveness towards pneumococcal diseases by serotype Pn 6A might be lower compared with the adults. Also, recently a new serotype Pn 6C has been discovered and considering reports on increase of $\mathrm{Pn} 6 \mathrm{C}$ in all age groups after routine immunization in children of the 7-valent pneumococcal vaccine are accumulating, close monitoring on the epidemiologic changes of these serotypes in the elderly is desirable [22-24].

Previous reports on the immunogenicity to the PPV in the elderly group show adequate mean immune responses, good antibody fold increase and comparable IgG antibody avidity with adults [7,8,25-27]. These reports are based on immunogenicity evaluated by ELISA. However, clinical data show various results related to the effectiveness of the vaccine, which leads us to acknowledge the need for additional methods of evaluation of the response to the vaccine.

Discrepancy between antibody function and antibody concentration in a clinical setting has been reported [6]. A passive-protection experiment in mice with S. pneumonia compared protection from two different sera with the same antibody concentration but different opsonic titers and antibody avidity. The serum with high opsonic titer and antibody avidity showed 100\% protection whereas no protection was observed with a serum with the same antibody concentration but low opsonic titer and antibody avidity. These results emphasize the importance of evaluation of antibody concentration and antibody function. Although the OPKA has been known as a labor intensive method, OPKA methods have been evolving rapidly and is now capable of evaluating multiple serotypes for many samples with only small amounts of sera [16,28-31].

This report highlights the importance of a quantitative and qualitative evaluation in this age group. There was a definite overall increase in opsonic titers after vaccination for all serotypes in the elderly, thus the recommendations for vaccination in the elderly should not be discouraged. Also, recently many countries have shown the cost-effectiveness of routine vaccination of PPV in the elderly $[32,33]$. However, due to the fact that the response in the elderly was weaker for some serotypes and individuals compared with adults, we emphasize the need of evaluation of functional activity within this age group when determining the immunogenic response. Also, with the vigorous development of pneumococcal vaccines, efforts to enhance this weaker response in this age group are warranted. Therefore, the results of this article could be invaluable in the development of the optimal vaccine and making decisions for the proper policy for pneumococcal vaccination in the elderly.

\section{Conclusions}

After vaccination with PPV, although the amount of antibodies elicited were similar between the two groups, distinct differences in function were noted. The immunogenic response to the PPV vaccine should be evaluated by the quantitative and qualitative response in this age group.

\section{List of abbreviations used}

PPV: 23-valent pneumococcal polysaccharide vaccine; ELISA: enzyme-linked immunosorbent assay; PS: polysaccharide; OPKA: opsonophagocytic killing assay; Pn: pneumococcal; GMC: Geometric mean concentration; GMT: geometric mean titer; GMP: geometric mean potency; GMI: geometric mean index; CI: 95\% confidence interval;

\section{Acknowledgements}

We thank Carl Frasch at Center for Biologics Evaluation and Research, Food and Drug Administration, Bethesda, MD. for providing us with the reference standard 89-SF

Source of financial assistance: This work was partially supported by a grant from KFDA 05092-341 to KHK.

\section{Author details}

'Department of Pediatrics, School of Medicine, Ewha Womans University, Seoul, Republic of Korea. ${ }^{2}$ Center for Vaccine Evaluation and Study, Ewha Medical Research Institute, Ewha Womans University, Seoul, Republic of Korea. ${ }^{3}$ Departments of Pathology and Microbiology, University of Alabama at Birmingham, Birmingham, Alabama, USA.

\section{Authors' contributions}

$\mathrm{HL}$ performed the primary statistical analysis, and wrote the bulk of the paper. KHK performed the laboratory assays and was the principal investigator for the study, reviewed and approved the analyses and contributed to the writing and revision of the paper. MHN supervised the laboratory work, reviewed and approved the analyses and contributed to the writing and revision of the paper. All authors read and approved the final version of the manuscript.

\section{Competing interests}

The authors declare that they have no competing interests.

Received: 28 August 2009 Accepted: 10 March 2010 Published: 10 March 2010 


\section{References}

1. Centers for Disease Control and Prevention (CDC): 23-valent pneumococcal polysaccharide vaccine. WHO position paper. Wkly Epidemiol Rec 2008, 83:373-384.

2. Fedson DS: The clinical effectiveness of pneumococcal vaccination: a brief review. Vaccine 1999, 17(Suppl 1):85-90.

3. Shapiro ED, Berg AT, Austrian R, Schroeder D, Parcells V, Margolis A, Adair RK, Clemens JD: The protective efficacy of polyvalent pneumococcal polysaccharide vaccine. N Engl J Med 1991, 325:1453-1460.

4. Moberley SA, Holden J, Tatham DP, Andrews RM: Vaccines for preventing pneumococcal infection in adults. Cochrane Database Syst Rev 2008, CD000422.

5. Romero-Steiner S, Frasch CE, Carlone G, Fleck RA, Goldblatt D, Nahm MH: Use of opsonophagocytosis for serological evaluation of pneumococcal vaccines. Clin Vaccine Immunol 2006, 13:165-169.

6. Romero-Steiner S, Musher DM, Cetron MS, Pais LB, Groover JE, Fiore AE, Plikaytis BD, Carlone GM: Reduction in functional antibody activity against Streptococcus pneumoniae in vaccinated elderly individuals highly correlates with decreased IgG antibody avidity. Clin Infect Dis 1999, 29:281-288.

7. Sankilampi U, Honkanen PO, Bloigu A, Herva E, Leinonen M: Antibody response to pneumococcal capsular polysaccharide vaccine in the elderly. J Infect Dis 1996, 173:387-393.

8. Rubins JB, Puri AK, Loch J, Charboneau D, MacDonald R, Opstad N, Janoff EN: Magnitude, duration, quality, and function of pneumococcal vaccine responses in elderly adults. J Infect Dis 1998, 178:431-440.

9. Rubins JB, Alter M, Loch J, Janoff EN: Determination of antibody responses of elderly adults to all 23 capsular polysaccharides after pneumococcal vaccination. Infect Immun 1999, 67:5979-5984.

10. Concepcion NF, Frasch CE: Pneumococcal type $22 \mathrm{f}$ polysaccharide absorption improves the specificity of a pneumococcal-polysaccharide enzyme-linked immunosorbent assay. Clin Diagn Lab Immunol 2001, 8:266-272

11. Coughlin RT, White AC, Anderson CA, Carlone GM, Klein DL, Treanor J: Characterization of pneumococcal specific antibodies in healthy unvaccinated adults. Vaccine 1998, 16:1761-1767.

12. Yu X, Sun Y, Frasch C, Concepcion N, Nahm MH: Pneumococcal capsular polysaccharide preparations may contain non-C-polysaccharide contaminants that are immunogenic. Clin Diagn Lab Immunol 1999, 6:519-524.

13. Wernette CM, Frasch CE, Madore D, Carlone G, Goldblatt D, Plikaytis B, Benjamin W, Quataert SA, Hildreth S, Sikkema DJ, et al: Enzyme-linked immunosorbent assay for quantitation of human antibodies to pneumococcal polysaccharides. Clin Diagn Lab Immunol 2003, 10:514-519.

14. Schenkein JG, Park S, Nahm MH: Pneumococcal vaccination in older adults induces antibodies with low opsonic capacity and reduced antibody potency. Vaccine 2008, 26:5521-5526.

15. Kim KH, YU J, Nahm MH: Efficiency of a pneumococcal opsonophagocytic killing assay improved by multiplexing and by coloring colonies. Clin Diagn Lab Immunol 2003, 10:616-621.

16. Romero-Steiner S, Libutti D, Pais LB, Dykes J, Anderson P, Whitin JC, Keyserling HL, Carlone GM: Standardization of an opsonophagocytic assay for the measurement of functional antibody activity against Streptococcus pneumoniae using differentiated HL-60 cells. Clin Diagn Lab Immunol 1997, 4:415-422

17. Weksler ME, Szabo P: The effect of age on the B-cell repertoire. J Clin Immunol 2000, 20:240-249.

18. Kline GH, Hayden TA, Klinman NR: B cell maintenance in aged mice reflects both increased $B$ cell longevity and decreased $B$ cell generation. J Immunol 1999, 162:3342-3349.

19. Musher DM, Chapman AJ, Goree A, Jonsson S, Briles D, Baughn RE: Natural and vaccine-related immunity to Streptococcus pneumoniae. J Infect Dis 1986, 154:245-256.

20. Zheng B, Han S, Takahashi Y, Kelsoe G: Immunosenescence and germinal center reaction. Immunol Rev 1997, 160:63-77.

21. Fedson DS, Musher DM: Pneumococcal Polysaccharide. Vaccines Philadelphia: SaundersPlotkin SA, Orenstein WA , 4 2004, 529-588.

22. Park $\mid H$, Pritchard DG, Cartee $R$, Brandao A, Brandileone MC, Nahm MH: Discovery of a new capsular serotype (6C) within serogroup 6 of Streptococcus pneumoniae. J Clin Microbiol 2007, 45:1225-1233.
23. Nahm MH, Lin J, Finkelstein JA, Pelton SI: Increase in the Prevalence of the Newly Discovered Pneumococcal Serotype 6C in the Nasopharynx after Introduction of Pneumococcal Conjugate Vaccine. J Infect Dis 2009, 199:320-5.

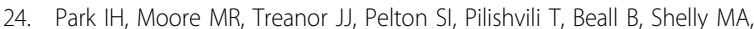
Mahon BE, Nahm MH: Differential Effects of Pneumococcal Vaccines against Serotypes 6A and 6C. J Infect Dis 2008, 198:1818-1822.

25. Musher DM, Groover JE, Graviss EA, Baughn RE: The lack of association between aging and postvaccination levels of IgG antibody to capsular polysaccharides of Streptococcus pneumoniae. Clin Infect Dis 1996, 22:165-167.

26. Konradsen HB: Quantity and avidity of pneumococcal antibodies before and up to five years after pneumococcal vaccination of elderly persons. Clin Infect Dis 1995, 21:616-620.

27. Carson PJ, Nichol KL, O'Brien J, Hilo P, Janoff EN: Immune function and vaccine responses in healthy advanced elderly patients. Arch Intern Med 2000, 160:2017-2024

28. Burton RL, Nahm MH: Development and validation of a fourfold multiplexed opsonization assay (MOPA4) for pneumococcal antibodies. Clin Vaccine Immunol 2006, 13:1004-1009.

29. Martinez JE, Clutterbuck EA, Li H, Romero-Steiner S, Carlone GM: Evaluation of multiplex flow cytometric opsonophagocytic assays for determination of functional anticapsular antibodies to Streptococcus pneumoniae. Clin Vaccine Immunol 2006, 13:459-466.

30. Romero-Steiner S, Frasch CE, Carlone G, Fleck RA, Goldblatt D, Nahm MH: Use of opsonophagocytosis for serological evaluation of pneumococcal vaccines. Clin Vaccine Immunol 2006, 13:165-169.

31. Henckaerts I, Durant N, De Grave D, Schuerman L, Poolman J: Validation of a routine opsonophagocytosis assay to predict invasive pneumococcal disease efficacy of conjugate vaccine in children. Vaccine 2007, 25:2518-2527.

32. Ogilvie I, Khoury AE, Cui Y, Dasbach E, Grabenstein JD, Goetghebeur M: Cost-effectiveness of pneumococcal polysaccharide vaccination in adults: A systematic review of conclusions and assumptions. Vaccine 2009, 27:4891-904

33. Smith KJ, Zimmerman RK, Nowalk MP, Roberts MS: Age, revaccination, and tolerance effects on pneumococcal vaccination strategies in the elderly: A cost-effectiveness analysis. Vaccine 2009, 27:3159-3164.

\section{Pre-publication history}

The pre-publication history for this paper can be accessed here: http://www.biomedcentral.com/1471-2334/10/60/prepub

doi:10.1186/1471-2334-10-60

Cite this article as: Lee et al:: The effect of age on the response to the pneumococcal polysaccharide vaccine. BMC Infectious Diseases 2010 10:60.

\section{Submit your next manuscript to BioMed Central and take full advantage of:}

- Convenient online submission

- Thorough peer review

- No space constraints or color figure charges

- Immediate publication on acceptance

- Inclusion in PubMed, CAS, Scopus and Google Scholar

- Research which is freely available for redistribution

Submit your manuscript at www.biomedcentral.com/submit
Biomed Central 